\title{
Loss and social-ecological transformation: pathways of change in Xochimilco, Mexico
}

\author{
$\underline{\text { Hallie Eakin }}^{1}$, Rebecca E. Shelton ${ }^{1},{\underline{J . M a r i o ~ S i q u e i r o s-\text { Garcia }^{2}}}^{2}$ Lakshmi Charli-Joseph $^{3}$ and David Manuel-Navarrete $^{1}$
}

\begin{abstract}
We explore how loss of livelihood, loss of ecological function, and loss of group identity are linked in the process of social-ecological change through the narratives of stakeholders associated with the wetland of Xochimilco in Mexico City. Drawing from interviews, focus groups, and participatory workshops with a variety of residents and city administrators, we analyze narratives about what is valued, what is problematized, and what social and ecological relationships appear as critical from the perspective of contemporary residents and officials. Loss is prominent in these narratives, capturing the interdependence of ecology, identity, meaning, and livelihood for the inhabitants. We trace these narratives to the historical roots of center-periphery politics of land and water use, situating the current dynamic context within the social-ecological system's long pathway of change. Diffuse blame for social-ecological change expressed in the narratives appears to inhibit collective action, as does a conflicted history of local response to the city's control of resources. We posit that finding a sustainable pathway forward may depend in part on how residents are able to cognitively or emotionally accommodate landscape change while still enabling the values they have come to associate with the landscape. Such accommodation may entail accepting some degree of loss in system function and structure, but this loss may also provide opportunities for new social-ecological relations that enable the persistence of local identity.
\end{abstract}

Key Words: identity; Mexico; sense of place; solastalgia; transformation

\section{INTRODUCTION}

We explore how loss of livelihood, loss of ecological function, and loss of identity are linked in the process of social-ecological transformation, referring to both substantive desirable and undesirable change, through an analysis of the narratives of residents of the borough of Xochimilco in Mexico City. Xochimilco is one of Mexico City's 16 boroughs and contains the last remnants of what was once, in pre-Hispanic times, an extensive wetland across the southern part of the Valley of Mexico. This wetland was one of five shallow lakes that supported a vibrant ecology and innovative food system, which together served as the primary source of sustenance for the valley's preHispanic population.

Today a fraction of that ecological and cultural history remains functional: a small but persistent population of farmers manage their traditional "floating agricultural islands" (chinampas) for subsistence and commercial production. Local and international tourists visit the wetland to float and drink on colorfully decorated trajineras, i.e., pole-steered flat-bottomed boats. Although of dubious quality because of pollution, fishers still harvest tilapia, which was introduced in a malinformed ecological control experiment, from the contaminated water. The borough is also culturally vibrant: although now the site of significant immigration and demographic change, neighborhoods continue strong religious traditions dating back hundreds of years. Original residents pride themselves in declaring their rooted identity: "we are Xochimilcas" rather than chilangos, i.e., the slang for the inhabitants of the capital city. However, steadily, over the last several decades, the urban fringe has encroached on the canals and agricultural plots in which there was formerly only traditional farming. With urbanization, much of it informal, without services, and modernization in agricultural technologies, water quality has become a significant concern. Despite significant investment by the city and international attention, including a designation as a UNESCO World Heritage Site in 1987, the wetland environment is in rapid decline. The political context is one of uncertainty, apathy, and anguish, with much debate and little cohesion over the best pathway forward.

We leveraged our engagement with local actors in this context to probe how the experience of ecological loss is reflected in sense of place as well as personal and collective identity, and how such experience relates to actors' motivations to intentionally alter the trajectory of development in Xochimilco. We focused not only on how actors have experienced trajectories of change, but also on how they explain it and ascribe responsibility. In doing so, we join others in the social-ecological and climate change research communities in calling attention to notions of immaterial loss associated with environmental change, the ways in which such loss is experienced, and the implications of such experience for individual and collective agency (Barnett et al. 2016, Tschakert et al. 2017, 2019, Masterson et al. 2019).

\section{MEANING, LOSS, TRANSFORMATION, AND ACTION}

Human emotional and cognitive relationships to place have been a subject of study for decades (Lewicka 2011) and have recently been taken up in social-ecological systems research and sustainability science to help explain motivation for environmental stewardship, adaptation to climate change, and the willingness of individuals to engage in sustainability transitions (Masterson et al. 2017). The concept of "sense of place" generally refers to both the practical and symbolic meanings that individuals or groups derive from a specific setting as well as the emotional bonds that form a sense of psychological attachment to place (Tuan 1977, Scannell and Gifford 2010, Masterson et al.

${ }^{1}$ School of Sustainability, Arizona State University, Tempe, Arizona, ${ }^{2}$ Instituto de Investigaciones en Matemáticas Aplicadas y en Sistemas (IIMAS), Unidad Mérida, Universidad Nacional Autónoma de México, Yucatán, México, ${ }^{3}$ Laboratorio Nacional de Ciencias de la Sostenibilidad (LANCIS), Instituto de Ecología, Universidad Nacional Autónoma de México, Ciudad de México, México 
Fig. 1. The Xochimilco urban wetland system. Map developed by LANCIS Collaborative Planning Lab (N. Ruiz, E. Villa Mendoza, and C. Cantero) with data provided by the Autoridad de la Zona Patrimonio Mundial Natural y Cultural de la Humanidad en Xochimilco, Tláhuac y Milpa Alta from 2013, and the Secretaria del Medio Ambiente from 2015 for the irregular settlements.

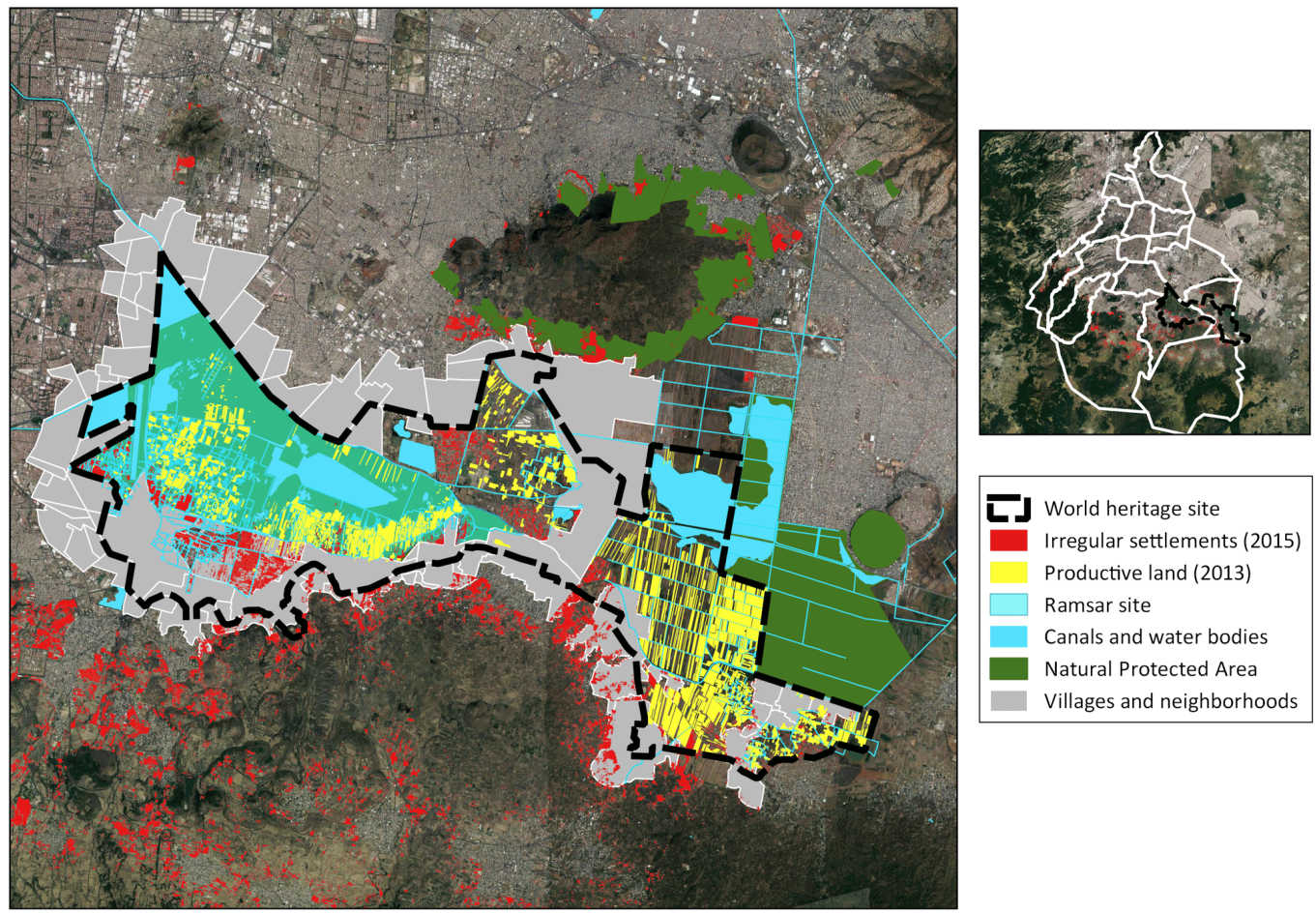

2017). Meaning is derived from patterns of livelihood activities and experience in a physical environment, as well as through the norms and cultural contexts that shape those activities and experiences (Masterson et al. 2017).

Attachment is theorized to be composed of one's dependence on a particular suite of resources and landscape attributes (e.g., for livelihood activities), as well as the relationship of one's identity to those attributes (Sack 1997, Lewicka 2011). Identity, i.e., one's sense of self, defined by specific physical, social, and cognitive characteristics as well as by one's relationship to others, is established in part through experience and activities associated with landscapes; in fact, some social psychologists argue that "all aspects of identity will, to a greater or lesser extent, have placerelated implications" (Twigger-Ross and Uzzel 1996:206). Specifically, four qualities have been identified as instrumental in the linkages between place and identity: distinctiveness (the use of place as a social attribute to distinguish oneself from others and to claim group membership), continuity (the use of place to preserve one's individual self-concept through reference to a place-based past), self-esteem (how place affects one's sense of self-worth), and self-efficacy (the capabilities offered by a place to realize one's goals; Twigger-Ross and Uzzel 1996). Place conveys specific meanings that reinforce agency, self-efficacy, uniqueness, and the emotions that convey a sense of self (TwiggerRoss and Uzzel 1996, Stedman 2002, Lai and Kreuter 2012, Carley et al. 2018).
Research on place attachment has led to an interest on whether such attachment provokes place-protective behaviors, such as environmental stewardship (Stedman 2002, Lewicka 2011, Chapin and Knapp 2015). Scholars have posited that it is not necessarily the threat to the intrinsic value or condition of a physical attribute in a place that provokes action but rather the threat to one of the given meanings associated with that attribute (Stedman 2003, Scannell and Gifford 2010), a threat that diminishes an attributes' ability to reflect identity/sense of self (Stedman 2002), or a threat to the human-nature relationship (Chan et al. 2016). Deeply held place meanings may be what in social-ecological research are considered slow variables: cognitions and values may change slowly given their interdependence on a scaffolding of social networks, institutional legacies, and associated activities (Masterson et al. 2017).

A growing body of scholarship, mostly in relation to climatechange impacts, has documented how place meaning, attachments to place, and the aspects of self-identity associated with place can be the subject of loss. Barnett et al. (2016:977) argued that "loss arises when people are dispossessed of things that they value, and for which there are no commensurable substitutes." In an era of unprecedented environmental change, they call for a stronger theorization of the relationship of the disparate dimensions of loss to the experience and anticipation of environmental change. Drawing on theory from psychology, it is generally understood that people are more likely to act to avoid loss rather than to achieve potential gains (Kahneman et al. 1991). 
Thus, as ecological change impacts cognitions and values, placeprotective behavior may be triggered by a sense of loss or situations framed as loss.

In the face of relatively rapid ecological change, potentially experienced as undesirable transformations of system function and identity, efforts to protect place meanings and reduce experience of loss can impede people from acknowledging the need for proactive social transformation in livelihoods and place relations. For example, research on individual risk perception and climate change in Australia found that strong place attachment may motivate adaptation to change under gradually shifting environmental conditions, but under more radical contexts of environmental change that threaten place meaning (such as threats to livelihood viability), such attachments may impede people from engaging in more (normatively positive) transformational responses (Marshall et al. 2012). Research in disaster recovery has found that sense of place is often what motivates communities to return back to the way things were, impeding them from taking the opportunity to implement more progressive and needed changes to their settings (Scannell and Gifford 2010).

It is not only the pace and magnitude of environmental change that may affect the probability of collective action toward a desirable system transformation, but the depth of emotional loss experienced. Tschakert et al. (2019), for example, found that across a diversity of case studies documenting the psychological impacts of climate change, there was evidence that climate change affects self-determination and influence, as well as the ability of individuals to act collectively. Ecological grief is a concept now being used to describe the sense of mourning and emotional loss reported in the experience of undesirable ecological change (Marshall et al. 2019). As landscapes undergo change, and, in particular, when that change is rapid, part of lived experience, and perceived to be out of the control of those who inhabit a landscape, residents can experience a sense of loss so severe that it is a source of physical and psychological harm and thus can serve as a demobilizing force.

"Solastalgia" is a term coined by Albrecht (Albrecht 2006) to capture the sense of "pain experienced when there is recognition that the place where one resides and that one loves is under immediate assault (physical desolation). It is manifest in an attack on one's sense of place, in the erosion of the sense of belonging (identity) to a particular place and a feeling of distress (psychological desolation) about its transformation" (Albrecht 2006:45). Significant and undesirable landscape transformations can imply alienation from one's self-concept or group identity (Lai and Kreuter 2012, Tschakert et al. 2013, Warsini et al. 2014, Marshall et al. 2019) with consequences such as post-traumatic stress disorder (PTSD), apathy, and despair (Doherty and Clayton 2011, Clayton et al. 2014). These consequential psychological impacts may have an impact on motivation or the ability to act in protection of place.

Place meaning and particularly place identity, however, is not only based on an individual's personal experience in a place, but also on shared memory, cultural history, and legacies of social groups contributing to one's sense of identity continuity (Twigger-Ross and Uzzel 1996, Scannell and Gifford 2010). In some cases, such shared associations with place can form the basis of symbolic communities in which identity is wedded to representations of the past contained within a particular setting (Scannell and Gifford 2010). These legacies can be motivations for resistance to change or sources of empowerment to promote change. Many of these historical legacies are articulated in group identity narratives regarding political struggles over resource use and management, assimilated into institutional norms, and contribute to disputed place meanings. Past and present power relations among different segments of society affect how any experience of place is perceived and interpreted, just as such power relations foster conditions conducive for some actions (place protective or not) over others (Stedman 2016, Masterson et al. 2019). Just as the emotions, identity, practices, and cultural rituals of individuals and communities can become coupled, over time, with surrounding landscapes, those landscapes and populations are also embedded in continually evolving and often long-standing political and social dynamics.

These social-political dynamics are reflected in landscape features that reinforce pathways of development, becoming symbolic representations of historical loss in relation to group identity and self-esteem. Aqueducts and wells, for example, reveal the power of specific groups in harnessing the direction and flow of hydrological resources; walls and roads manifest lines of property and economic ties; the presence and condition of mines, agricultural fields, or urban development visually underscores which economic and social values are dominant or which are marginalized (Harner 2001, Widdifield and Banister 2015, Morehart 2018). This social-political infrastructure (Eakin et al. 2017) contributes to residents' sense of place and loss: their complex identities are formed not only in terms of the positive relational values associated with geographic attributes (caring, stewardship, happiness, peace, self-efficacy, etc.) but also by longstanding social relations of power, extraction, control, and choice (Masterson et al. 2019).

Such complex and contradictory emotive connections to place likely complicate collective action. If a specific individual, agent, or causal factor can be identified as being culpable for the loss experienced, action may be more likely than if blame is diffused across multiple actors and factors (Stone 2002, Javeline 2003). In addition, scholars have argued that collective action is more likely if there is some kind of organization or socially constructed channel into which to mobilize discontent (Hardin 1982). For example, if social ties are weak or bridging social capital (the type of social ties that link actors or groups to other actors or groups and the state) is low, which may be the case given particular histories of colonization or development, collective action may not surface in spite of widespread sense of loss, betrayal, and resentment (Adger 2003).

Thus, although it can be concluded that the relational values and psychological ties humans have with their surroundings are critical factors in the experience of and responses to environmental change (Barnett et al. 2016, Masterson et al. 2019), more research is needed to understand the conditions in which these values and ties provoke or impede adaptive, sustainable social and ecological transformation (Andrachuk and Armitage 2015). 


\section{XOCHIMILCO, MEXICO CITY}

The wetland area of Xochimilco, the last remnant of the complex lacustrine system of wetlands in the Basin of Mexico, has a long cultural and land-use change history. As early as 1000 years ago, the populations living around the five shallow lakes in the Basin developed the chinampa agricultural system (Morehart 2018), a type of Mesoamerican agriculture consisting of rectangular, floating fields, bordered and contained by tall wetland-tolerant trees, to grow crops within the shallow lake (Ezcurra et al. 2006, Pérez Mujica 2012). After the Mexica violently conquered the local populations and established Tenochtitlan in the center of the basin in the 14th century, the chinampas became a central part of the Aztec economy, culture, and food provisioning system (Rojas Rabiela 1991, Morehart 2018). Confronted with periodic flooding that threatened the viability of Tenochtitlan, the Aztecs constructed elaborate hydrological infrastructure: dykes and sluices to prevent the mixing of the saline waters of Texcoco (one of the shallow lakes) with Xochimilco's relatively fresh, springfed system (Tellman et al. 2018). The infrastructure served the Aztecs' goal of controlling and expanding chinampa production as a primary source of food, extracted through a system tribute and control of landholdings (Morehart 2018). Thus, although the day-to-day maintenance of the chinampa agroecosystem was the charge of the Xochimilca farmers and laborers of the wetland, their livelihood and the productivity of the chinampas also became economically and hydrologically dependent on state (Tenochtitlan and Xochimilca) intervention and investment in large infrastructure (Morehart 2018).

During the colonial era, the wetlands were urbanized and drained, and the remaining waters became contaminated with urban wastes (Tellman et al. 2018). By the turn of the 20th century, Xochimilco's wetland was one of the last remnants of the preHispanic lakes. Water scarcity in the city prompted Mexico's president to order the springs feeding the wetland to be tapped and channeled to satisfy the city's thirst (Cirelli 1997, Widdifield and Banister 2015) and within three decades the wetland was nearly desiccated. Growing water scarcity in Xochimilco motivated perforation of wells to supply the local population (Romero Lankao 2010), and this, in turn, created conditions of subsidence affecting the hydrological function of the degraded wetland. In the $1950 \mathrm{~s}$, the city moved to artificially supply the wetland with treated waste water from the neighboring urban area of Iztapalapa (population of $>1.3$ million) and the wetland began to serve an additional function for the city as a stormwater retention basin.

Today the Xochimilco urban wetland is a fraction, perhaps only $1 \%$ (Morehart 2018), of what it once was. It is a site of contrasting land uses, including traditional (chinampas) and conventional agriculture, greenhouses, urban activities, and tourism, with the urban expansion of Mexico City as the main threat (Merlín-Uribe et al. 2013). Water quality has declined, not only because it is now fed by Iztapalapa's waste waters, but also because of numerous illicit discharges of sewage into the wetland from the irregular and expanding urban settlements on the wetland fringe (see Fig. 1) as well as the use of chemicals, including heavy metals and pesticides (Mazari-Hiriart et al. 2008). Water quality concerns have undermined fishing and agricultural livelihoods, and threaten the ecotourism activities of the area (Zambrano et al.
2009). Other pressing issues include water shortages, floods, differential land subsidence, invasive species, and biodiversity loss (Zambrano et al. 2007).

Efforts to conserve the wetland have not been very successful. Since the 1970s, there have been diverse initiatives to attempt to better regulate the development in the wetland and protect the ecology through various forms of conservation designations, including its recognition as a RAMSAR wetland in 1971 and a UNESCO World Heritage Site in 1987. Around $80 \%$ of the wetland's area is intended for ecological conservation and agricultural production (named Conservation Soil), whereas 20\% is urban land.

However, urbanization has steadily increased over the decades (Fig 2). The expansion of illegal and unregulated settlements into the wetland is often incentivized through electoral politics. Despite land-use prohibitions against residential use in protected areas of the area, an estimated $25 \%$ of the protected wetland area is currently urbanized. Furthermore, only 17\% (3586 of 20,922) of the remaining chinampas are considered active (González Pozo et al. 2016). As land use and economic activities have changed in the area, the meaning associated with the wetlands have also evolved and diversified: Xochimilco is not only a place of traditional farming and cultural heritage, but of weekend tourism, of informal urban residence, a site of intensive water resource intervention, and a habitat of ecological importance. These meanings are not always compatible or equally present in the decision processes that have significant influence on the wetland's future.

Fig. 2. Time series 1500-2010. World Heritage perimeter (red), water bodies (blue), and urban sprawl (black) through time (developed by F. Serrano).

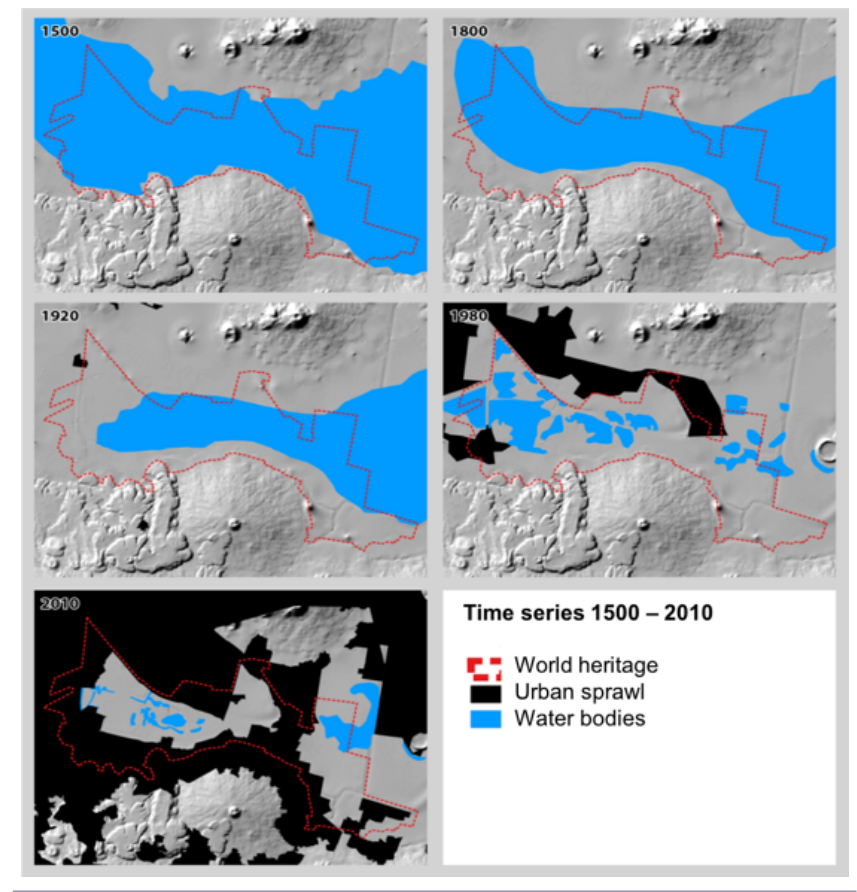




\section{METHODS AND APPROACH}

Our analysis is based on two sources of data and two research approaches, neither of which were explicitly designed to evaluate sense of place. Nevertheless, as inductive research, the qualitative approaches we pursued revealed the salience of place, identity, and loss, and thus these constructs have served an important role in interpreting our findings.

The first set of data was from a series of eight mental model interviews (Morgan et al. 2002, Cone and Winters 2011) and five workshops that took place over the course of 2014-2015. These data encompass individual interviews with five representatives from the local government of the Xochimilco borough (representing departments of environment and sustainability, cultural heritage, urban development, water infrastructure, and ecology), two representatives of the Xochimilco World Heritage Site Authority, and a group interview with five additional representatives of distinct sector departments from the local government (thus seven individual interviews, and one group interview with five actors). In addition, we organized five participatory workshops with, respectively, (1) eight representatives of a fishers' association, convened by a key informant from the association, (2) three different groups of chinamperos (five-eight participants in each workshop), and (3) with resident representatives of the San Gregorio urban neighborhood.

The individual interviews entailed a protocol designed to let the interviewee speak openly without significant prompting about the issue of water in the borough. The interviews typically lasted one to one and a half hours. The instructions were not to focus explicitly on the wetland, nor on the administrative boundaries, but rather on the area of Xochimilco. The interviews were transcribed and coded, and key concepts (variables or system elements) mentioned by the interviewee were extracted along with the relationship of these concepts to other concepts in the interviewee's narrative.

The participatory workshops involved a sequence of activities that were conducted over the course of two to three hours (halfday). These workshops followed a protocol that began with a rich picture exercise (Checkland and Poulter 2006) to elicit the participants' understanding of their system of interest, followed by a problem-tree analysis exercise (associating problems, represented as tree leaves, identified in the rich picture to root causes), and finally, a collectively produced and validated influence diagram (Morgan et al. 2002). This influence diagram was a collective mental model representation, capturing the network of identified relationships among system elements believed to be generating distinct outcomes.

Each interview and workshop resulted in the synthesis of information in an undirected matrix of related terms, or, in other words 13 (from 8 interviews and 5 workshops) different mental models represented as matrices. Through methods of network representation, we created communities of terms from the collection of 13 matrices, representing, in our case, dominant narratives, that are highly connected and represented by the most central node (highest ranked) in each community (see SiqueirosGarcía et al. 2019 for details on the methodology). These narratives are interpreted in relation to the terms that define them. We illustrated these narratives by returning to the original qualitative data to provide insights into how the respondents characterized each narrative.
The second approach involved an intensive participatory process: a transformation laboratory or T-lab, which we embarked on in 2016 (Charli-Joseph et al. 2018). This second approach was intentionally interventionist, designed to build on the knowledge gained in the interviews and prior workshops to create a context that would potentially lead to normatively positive transformative social action at a personal, practical, or even political level in Xochimilco (O'Brien and Sygna 2013). In this context, the objective was to create the context for collective agency, as a basis for intentional, and normatively desirable, social transformation (Charli-Joseph et al. 2018). We invited the participation of a small, intentionally selected group of 12 stakeholders. These stakeholders did not participate in the individual interviews or prior workshops, but had a similar range of livelihood orientations and responsibilities (e.g., five are chinamperos, two are residents and activists with informal settlements, five are associated with civil society groups working in sustainable agriculture, rainwater harvesting, or ecological restoration, and five are associated with local government or city-level public agencies). They were invited to the T-Lab after initial interactions with the research team that served to assess their roles in active social networks interested in social-ecological change, their dependence on the resources and/or knowledge of the issues facing the wetland, and their openness to experimental approaches and participatory methodologies (see Charli-Joseph et al. 2018 for additional details). We hypothesized that such actors would be open to explore the values and assumptions they held regarding change in the wetland, and their roles in relation to this change, and thus that we might be able to collectively discover new, and potentially transformative, pathways toward more effective action.

The T-Lab process entailed asking the participants to create visual and tactile representations (i.e., with clay, twigs, leaves, paper, small objects, and figures of plastic, etc.) of what they valued in Xochimilco, and to discuss and share the underlying meanings and emotions that the objects represented. Combining these representations, the participants created a composite "map" of Xochimilco representing common meanings, values, and emotional connections to the place. The workshop closed with an exploration of strategies to protect the meanings they derived from Xochimilco (if not the associated material objects).

\section{RESULTS}

\section{Dominant narratives}

The analysis of the interview data revealed a collection of overlapping narratives about Xochimilco, its current state, and trajectory (Fig 3). We describe four of the more prominent narratives: (1) loss of chinampero vocation, land use, and livelihood; (2) conservation of the chinampa agroecosystem; (3) loss of water quality; and (4) control over water supply.

\section{Loss of chinampero vocation, land use, and livelihood}

The most dominant narrative emerging from the interviews focused on the loss of the agricultural areas, the chinampas. In this narrative, their disappearance is associated with a change in agricultural productivity, the filling-in of the small canals that divide the chinampas (inhibiting water flow) by the chinamperos themselves, the desiccation of springs, the influx of migrants, and the effects on production and well-being. In this narrative, there are multiple causes of loss: land-use change is associated with a 
Fig. 3. Communities of terms from the mental models of the 13 interviewees in Xochimilco. Each node represents a suite of terms that are strongly associated with each other, thus conforming a broader narrative. The different narratives share some terms, represented by the thickness of the lines connecting each community of terms.

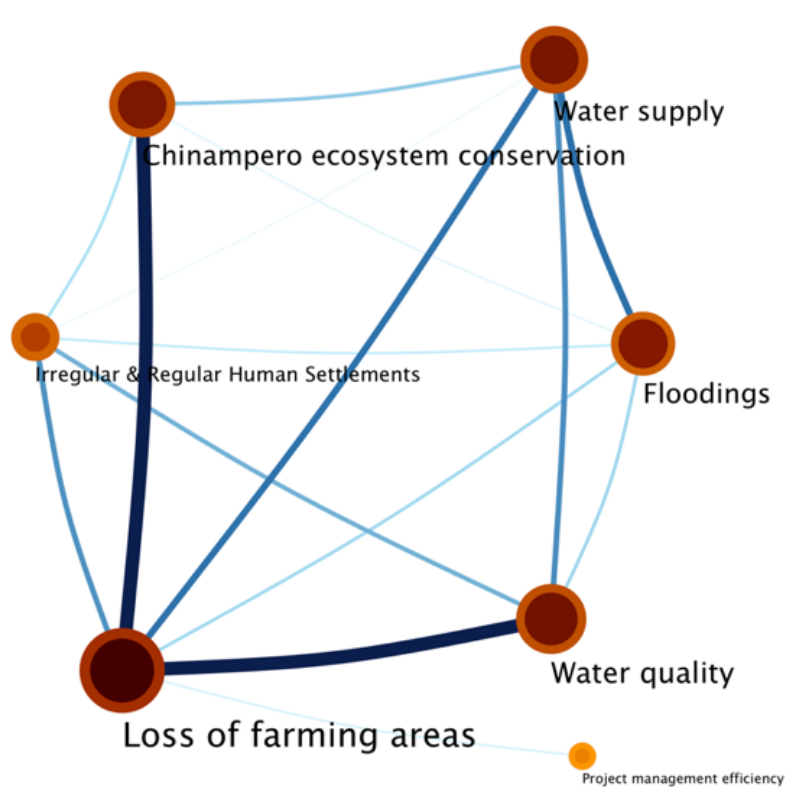

lack of public investment in traditional farming, lack of interest in farming in the younger population, and a devaluation of the agrarian identity of the chinampero.

Prominent in the narrative was the recognition that "there's a lack of interest in the youth..." The children of the chinamperos, returning to inherit the land, are place-disoriented, unable to place themselves "including the location of their [parent's] properties." Several authorities blamed television and the education system for devaluing the traditional farming practices and turning even local chinamperos against the idea that their children should continue farming. Even the farmers who were attempting to continue production were often criticized by the interviewees as failing to maintain the traditional practices of farming. One respondent (government) described what he perceived as hypocrisy: the residents of one community claim to be proudly chinamperos but their practice entails agrochemicals, greenhouses, and a dedication to commercial flower production "all of which produces an extraordinary expenditure in pesticides and agrochemicals, which end up in the water."

Public investments intended to support alternative economic activities for residents (food stands or boat tours for tourists) were thought to have failed because they did not speak to the vocational ties of the chinamperos to the land. The government was blamed for allowing (irregular) urbanization of the wetlands through negligence and corruption.
... they allow house construction even though it alters the environment and there are legal restrictions... but they fall into corruption and evil ways: 'no one sees you, build it here.'

The chinamperos still see the vestiges of agrarian origin in the new urban settlements, mostly informal and illegal, which have encroached on the wetland.

You can see the creation of narrow, very labyrinthine streets that respond more than anything to the obligatory adaptation of the chinampas area with its small apantles, which are the smallest channels [for water] that now [filled in] allow communication within these [urban] neighborhoods.

The layout of the new settlements thus are physical testimony of the area's recent agrarian history and its loss.

Conservation of the chinampa agroecosystem

A closely related narrative was that of the ecological implications associated with the loss of the chinampero livelihood. Various interviewees saw a reinforcing feedback between ecological conditions and the presence of active chinamperos, and the public agencies that make farming possible. Interviewees argued that the aquatic agroecosystem depended heavily on the daily activities of chinamperos to maintain its integrity: keep the canals clean of invasive species (water hyacinth), defend the unique trees that border the chinampas from attacks to their roots by the now overprevalent tilapia, and to upkeep the soils and vegetation of the beds themselves. One interviewee commented that
.... in face of the loss of chinamperos, [there is a] loss of alternative labor that would be in charge of helping to clean out the canals...now we need to beg the government for labor support, which implies resources that the government doesn't have...

Another interviewee noted that the narrative of ecological decline and abandonment had even taken hold on the youngest generations. He recounted a story of a young boy who stood up in front of the local authority and declared that

$$
\begin{aligned}
& \text { in five years Xochimilco will be dead, and you know, the } \\
& \text { issue of subsidence, and our houses are going to collapse } \\
& \text { and the waters are filled with mud and muck. }
\end{aligned}
$$

Noting the loss of cultural identity that accompanies the change in vocation and ecosystem function, he commented that the children don't know

the silence, the productivity of the chinampa; this is a factor that is going to hit us the hardest, the migration; they are the children of people who came to live in Xochimilco, there isn't any reason that they would know about water.

Loss of water quality

The decline in water quality, the lifeblood of the wetland system, was as prominent a narrative as that of broader ecological decline. Again, the cause of loss was diffuse: interviewees associated the water quality with contamination of the wetland from 
agricultural residues and unregulated sewage from irregular housing, as well as from the intensity of tourism activities on the water. Water quality was particularly a concern among the remaining fishers in the lake, as well as the chinamperos who were attempting to pursue the more traditional means of production.

People don't purchase products from Xochimilco because they know they are contaminated with treated wastewater... it doesn't even pass through their heads that the water is treated, rather they think 'dirty' and from the beginning this [framing] sticks.

The perceived or actual decline in water quality depressed agricultural prices and "implies a strong impact on farmers" economy, well-being, and lifestyle."

They also associated the shift in water quality as a product of the historical intervention of the city into the wetland's water supply. In the $1950 \mathrm{~s}$, after the natural springs that fed the wetland were diverted to supply the city, treated sewage water was used to replenish the wetland. Although public officials reported that the water passed the standards of the city, studies by university experts have cast doubt on these data. Recognizing that the water was not only the treated sewage but also mixed with the effluent from hundreds, if not thousands of illegal sewage outlets, few experts trusted the quality of the water:

Now if I put my hand in, I'd have to wash it with alcohol, because now, now no one would dare to dive into it!

The change in quality of water implied a loss not only of instrumental value (the value of production for the farmers) but also of culture. The interviewees commented that the archeological evidence indicated that

it was [the god of water] Tlaloc who commanded the area, as the lord of water... and there is a tree that references Tlaloc, an ahuehuete that is more than 800 years old; that is testament to the amount of water that there was, because the tree couldn't have survived any other way in these soils.

Today they see in the contamination of the wetland and the replacement of the natural source of water with sewage as an affront to their religious origins and history.

The decision to contain the springs in pipes, and you know the outcome in terms of ecological equilibrium that we've experienced here, which is, in summary, the story of Xochimilco, and addresses the religious imaginary, with its icons linked hand in hand with water; this is the central issue and above all, what we understand forms part of the collective representation of the community.

Control of the water supply

The fourth narrative of the interviewees was one focused on water supply, and the issues associated with groundwater extraction, water infrastructure maintenance, and control by the city authorities. In the narrative, the perforation of wells locally to extract potable water to substitute the loss of the springs is tied to accelerated subsidence and "un-leveling" of the lake bed, causing considerable problems associated with the flooding of chinampas and/or a lack of depth for navigation.
Control over water supply, like quality, is intertwined in the community's sense of self-esteem and identity. The history of water control was perhaps even more present in the interviews than the physical and social conflicts and harm resulting from water management. One interviewee associated the flow of water to the city with the tribute of food from the chinampas paid by the Xochimilcas during the Aztec era:

what the Aztecs requested from the Xochimilcas was tribute but in food...for this reason we had the tradition of the canals and taking products to the center of the city...the Canal de la Viga, the Canal Nacional...those waterways went to the center...but somehow there persists a resentment towards the center, whatever is proposed by the government the people are going to reject it, the people are stubborn...they always argue that the city has exploited us, has taken things from us.

Another commented that

...the vision Xochimilca is the same as the national vision of oil production... we being $100 \%$ producers of water.. we are an aquatic community, we have to provide water to the city and as a result do not have sufficient for our own needs.

The concern was not just of the loss of control and power over such a key resource, but also what it implied in terms of the selfesteem and character of the Xochimilcas:

we were never friends of the Aztecs, the Mexicas...the Mexicas were bad to us, we weren't warriors, we were farmers, we didn't fight, they conquered us and then were conquered by the Spanish... we've never gotten along very well with the city.

One interviewee was somewhat irritated by this prevalent defensive narrative of the conquered population:

the problem arises here because the Xochimilca culture
is very rooted, protected; always in opposition to the
government, the universities, other communities; always
thinking that they are going to invade, that they are going
to do harm; they have made modernity a synonym with
the loss of culture, this has been very strong and they still
can't get it that modernity is not in conflict with identity.

Identity

In all of the narratives and interviews, the interviewees presented a clear tension between the recognition that their history was one of political domination, paying tribute, and resource extraction, and the uniqueness of the local agroecosystem and wetland that defined the place and cultural identity of Xochimilco. On the one hand, the interviewees express resentment and defeat, arising from their social identification with the past represented in the place, with negative implications for self-efficacy and self-esteem, and on the other hand, significant pride in how their way of life as chinamperos is one of autonomy, self-efficacy, and self-reliance. In this sense, the four attributes of place identity described by Twigger-Ross and Uzzel (1996) were at odds. The socially constructed landscape of the chinampas, the canals, and now the wells, pumps, and sewage pipes reflected this tension: a source of 
Table 1. Meanings, emotions, and the associated physical and symbolic landscape.

\begin{tabular}{|c|c|c|}
\hline Boundary object & Associated meanings & Associated feelings \\
\hline The two chinampas & $\begin{array}{l}\text { inheritance, belonging, self-sufficiency, self- } \\
\text { efficacy, beauty, biodiversity, place attachment } \\
\text { (arraigo al lugar) }\end{array}$ & $\begin{array}{l}\text { satisfaction, nostalgia, memories of } \\
\text { childhood, frustration, sadness, lack of } \\
\text { respect, and "feeling that one is contributing } \\
\text { to bettering the world" }\end{array}$ \\
\hline $\begin{array}{l}\text { The four objects...(niñopa, chinampa, the tree of } \\
\text { San Juan, Urrutia bridge) }\end{array}$ & $\begin{array}{l}\text { unique identity, wealth, belonging, economic } \\
\text { vitality, resistance, persistence, ties to land, self- } \\
\text { sufficiency, independence, beauty }\end{array}$ & $\begin{array}{l}\text { pride, solidarity, intergenerational } \\
\text { connectivity, satisfaction, strength, love, } \\
\text { connection to the past }\end{array}$ \\
\hline $\begin{array}{l}\text { The conceptual map (water, the chinampas, } \\
\text { buildings, and the world) }\end{array}$ & belonging, identity, autonomy & $\begin{array}{l}\text { anger, nostalgia, sadness, love, happiness, } \\
\text { passion, peace }\end{array}$ \\
\hline
\end{tabular}

pride but also a material representation of centuries of contestation over the control of the resources that they felt made their livelihoods, ecology, and culture viable.

The people here in Xochimilco are very noble of heart... but also stigmatized by the pull of their ancestral roots.

In fact, the tradition of local chinamperos is to bury a child's umbilical cord in the soil of the chinampa when he or she is born; the word arraiga (rooted) is used often to describe the ties of the residents to the land. One respondent commented that some of the chinamperos active today

returned to the chinampa, they were formerly chinamperos, their parents, their grandparents, and they themselves as children; obviously they went to university, had a profession, they left, they retired, and they return to the chinampa not for nostalgia's sake but because the activity itself pulls them... above all as almost a vocation of the conservation of their origin.

Nevertheless, leveraging these strong bonds to the landscape and place as a means of place and self-concept conservation seemed to confound the interviewees:

the social part is what we haven't been able to do, not even visualize, I'm not saying that we ignore it, but rather we need to attack it directly.

\section{Results from the participatory workshop}

Our aim in the workshop was not to focus on the problem depiction (as was done in the mental model interviews) but rather to understand the meanings and values of place that the participants associated with particular biophysical elements of the landscape and explore the barriers that prevented the system from moving to a more desirable pathway that would conserve those meanings. The participants thus worked in three different groups to create representations (boundary objects) of what was meaningful to them in Xochimilco. What emerged from this exercise was three very distinct representations: first, a diorama of two chinampas, complete with local flora and fauna; second, a suite of four figures: an age-old ahuehuete tree, i.e., the tree of San Juan, the religious icon the niñopa, the Utturia Bridge, and a representation of a chinampa; and third, a conceptual map containing a drawing of water, the chinampas, and residential buildings linked by arrows to sketches of the map of Mexico and the world. Each of these representations was articulated to the rest of the group in terms of their associated meanings and emotions (Table 1).
After some discussion, the participants synthesized the meanings expressed in the exercise into three interrelated concepts: (1) Xochimilca cultural identity and resistance; (2) economic and vocational self-sufficiency and independence; and (3) unique esthetic (and ecological) experience. A new object, composed of words written on a large brown paper, was created collectively to capture these ideas; together these ideas and associated emotions represented a re-expression of the system in terms of deeply held meanings rather than geographic attributes.

The process of identifying the barriers for preserving the meanings that they valued was perhaps the most fundamental, but most challenging exercise of the group. The participants brought up the high rate of alcoholism and domestic violence in their communities, and the low self-esteem and helplessness of some of their neighbors. They commented on the socially devalued image of Xochimilco farmers, and the absence of social cohesion and solidarity among the agricultural communities. They reframed the barriers facing change in Xochimilco in terms of the emotional relationships the participants had with their environment and with each other, rather than the technical knowledge about the physical degradation of the environment per se. The workshop ended with the participants reflecting on their own roles in protecting and supporting the attributes they most valued in Xochimilco. Although they might not be able to alter the pipes that supplied the water to the wetland, or directly halt the corruption that was leading to urban expansion, they could alter their own mindsets and begin to build ties with neighbors, support each other in meeting immediate needs, and address the self-esteem of their community. The effort would need to be as much internal and psychological as external and material: "We have to 'change the chip,' no one is going to help us but us."

\section{DISCUSSION AND CONCLUSION}

Recent commentary on nonmaterial and intangible losses associated with climate change argues for making heard the firstperson and grounded voices that articulate what is valued, and how what is valued is derived from place and place experience (Barnett et al. 2019). Masterson et al. (2019) further stressed that such place-based understandings are inevitably political (in contexts of rapid change, whose meanings' count?) and can be associated with both conditions of feeling trapped as well as enabling novel courses of action. The participatory engagement with actors in Xochimilco described above provides insights into the depth of place attachment, as well as a shared sense of loss. The mental models revealed that the problem of Xochimilco was, 
in fact, also (or principally) a problem of loss in meaning associated with place, and thus a threat to identity of being Xochimilca as well as being chinampero. Meaning, and loss of meaning, was expressed in terms of the descriptive language used by the interviewees to describe what is, and is valued (beauty, noble, rooted, silent, miraculous), but also what has been altered (dirty, contaminated, muck). The interviewees, and the participants in the workshop, also identified key symbolic meanings threatened by environmental change: water, and its religious, political, and cultural significance; the ahuehuete trees, that symbolically and materially hold the chinampa together; the chinampa itself, and its implications of self-reliance, self-efficacy, and autonomy, but also, problematically, as a symbol of continuity of identity with long established historical relationships of resource extraction, tribute, and external control.

Scholars have found that shared meanings among a population can enable collective action, whereas a qualitative diversity of meanings, at least at the local level, may induce conflict and impede collective agency (Lewicka 2011, Masterson et al. 2017). The interviews and the workshop demonstrated that there are a diversity of meanings associated with the wetland, related to the distinct instrumental uses and conditions of the wetland system. The workshop illustrated that underneath these instrumental meanings, actors shared deep emotional ties to the wetland, and that these ties were being threatened. As the place around them was changing, the autonomy and control (self-efficacy) that the interviewees associated with Xochimilco identity was being undermined. Where umbilical cords were once "planted" among vegetables, concrete block houses now stand, sinking into the porous soils. Canals are transformed to narrow filled-in walkways, undermining agricultural self-efficacy, a core component of place identity. They saw the next generation of inhabitants seeking meaning and identity in relation to the city rather than to the aquatic ecology. The source of "miraculous" water, i.e., the springs that once fed the wetland, are long gone; the wetland, like the vocation of the chinamperos, now has an identity and vitality both maintained and undermined by its dependence on an artificial supply of wastewater.

It was difficult for the interviewees to pinpoint the primary cause of the changes they were experiencing. Literature in political science proposes that easily identified blame can serve to motivate individuals to engage in collective action whereas diffuse blame, particularly in political systems in which authority and governance systems are not transparent nor easily understood, may impede action (Stone 2002, Javeline 2003). Although narratives of causality were shared among different actors, we captured narratives rather than a single narrative. Within each narrative, there was not a singular actor or group that was blamed for the loss of the chinampa, the loss of ecological functions, or of water quality. This diffuse rather than directed blame seemed to disempower rather than motivate political or collective action.

The lack of collective agency may be a result of the long history of social-ecological change (indeed, transformation in a normatively negative sense) and loss of control that Xochimilco and its residents have already endured, generating an unrecognized deep trauma that has not been explicitly addressed over the generations that have experienced it. Masterson et al. (2019:559) argued that a critical component of understanding social-ecological change is through insight into "whose place meanings dominate in contested spaces and why." The actors of Xochimilco are acutely aware that their loss of control over their water was not a recent event but rather occurred over a century ago as it was tapped for Mexico City. The water that was once the source of collective identity and spiritual meaning for the population (spring), is now a source of repulsion (treated waste), and an impediment for those struggling to maintain self-efficacy in relation to their traditional way of life. Chinampas are increasingly given meaning by others: the tourists, environmental community, and water managers whose meanings have come into play in resource management. Those farmers who are struggling to maintain their agrarian traditions face a shift in public perception that agriculture is part of the problem, not a source of ecosystem vitality. These long-term processes of change and loss of control have given rise to a shared solastalgia, low selfesteem, eroded social cohesion and solidarity, and thus damaged the social organization needed for collective action (Adger 2003, Tschakert et al. 2019).

Brown (1987) argued that control over place plays a significant role in developing place-based affections, and sentiments of control over place and self also contribute to the self-efficacy required to engage in place-protective behavior (see also Anton and Lawrence 2016). For the chinamperos, mobilizing to protect the meaning(s) of Xochimilco implied confronting the reality that these meanings are now quite different for those actors and agencies, including neighboring chinamperos and the youth in the area, that have significant power over the wetland's trajectory of change.

It is in moments of system disorganization and perceived senselessness that some actors may mobilize in sense-making activities aimed at profound system change (Westley et al. 2013, Stedman 2016). In this context, the strategy we took in the workshop to separate what was valued as part of Xochimilca identity (self-reliance, stoic resistance, aesthetic appreciation) from the (threatened) material attributes that symbolized those meanings, was to some extent successful. In a sense, this exercise began a process of inquiry into what must be considered lost (irreplaceably gone), damaged (harmed but potentially capable of being restored), or at risk (see Tschakert et al. 2019). The approach allowed the participants to begin to consider that aspects of their identity need not be lost because the world changed around them; that there might be opportunities to realize that identity in attaching familiar meanings to new activities and practices that they could engage in as their landscapes also evolved, thus preserving what Twigger-Ross and Uzzel (1996) described as self-coherence. Organizing a system around shared values but a different materiality requires that actors engage in new sense making and building new social networks (Westley et al. 2013). How, for example, might they interact with residents in the urban settlements to communicate their place attachment and meanings? What cultural activities could they engage in that would enable them to share, without commodification, their identity with newcomers and tourists to the area? Through the Tlab process, participants began to consider and grapple with the idea that place identity might persist in some form even as some of the physical attributes of Xochimilco might be irrevocably altered. 
The participants in the workshop posited that their first step would be to recognize the psychological impact of the changes they were experiencing and find collective agency in coping with that loss directly. Ultimately, however, we imagine that collective agency of the wetland residents will reside in not just acceptance and coping, something that they recognize they have already done for centuries, but rather activating the other dimensions of what they recognize as essential elements of Xochimilca identity: resistance, solidarity, and self-reliance. By confronting the socialpolitical history that has constructed their place, and their own role in contemporary change processes, they may find ways to exert control over what new, or old, meanings are privileged and protected.

Responses to this article can be read online at: http://www.ecologyandsociety.org/issues/responses. php/11030

\section{Acknowledgments:}

We thank all the Xochimilco T-Lab project participants and project interviewees for their valuable time, effort, and interest in sharing their experiences and knowledge. We thank N. Ruiz, E. Villa Mendoza, C. Cantero, and F. Serrano for preparation of figures. $B$. Hernández for support in the mental model processing and data collection, A. Martinez for assistance in data collection, and B. Ruizpalacios for support in logistics and data gathering in the $T$ Lab process. This research was supported by the National Science Foundation under Grant No. 1414052, CNH: The Dynamics of Multi-scalar Adaptation in Megacities (PI, H. Eakin) and the Pathways to Sustainability Transformations to Sustainability Project, which is coordinated by the STEPS Centre UK (https:// steps-centre.org/globall), sponsored by the International Science Council and funded by the Swedish Development Cooperation Agency, and implemented in partnership with the National Research Foundation of South Africa. Any opinions, findings, and conclusions or recommendations expressed in this material are those of the authors and do not necessarily reflect the views of the sponsoring agencies. We appreciate the insightful comments and suggestions of the editor and two anonymous reviewers.

\section{LITERATURE CITED}

Adger, W. N. 2003. Social capital, collective action, and adaptation to climate change. Economic Geography 79 (4):387-404.

Albrecht, G., G.-M. Sartore, L. Connor, N. Higginbotham, S. Freeman, B. Kelly, H. Stain, A. Tonna, and G. Pollard. 2007. Solastalgia: the distress caused by environmental change. Australasian Psychiatry 15:S95-S98. https://doi.org/10.1080/103$\underline{98560701701288}$

Andrachuk, M., and D. Armitage. 2015. Understanding socialecological change and transformation through community perceptions of system identity. Ecology and Society 20(4):26. http://dx.doi.org/10.5751/ES-07759-200426

Anton, C. E., and C. Lawrence. 2016. The relationship between place attachment, the theory of planned behaviour and residents' response to place change. Journal of Environmental Psychology 44:145-154. https://doi.org/10.1016/j.jenvp.2016.05.010

Barnett, J., P. Tschakert, L. Head, and W. N. Adger. 2016. A science of loss. Nature Climate Change 6(11):976-978. https://doi. org/10.1038/nclimate3140 Barnett, J., P. Tschakert, L. Head and W. N. Adger (2016). "A science of loss." Nature Climate Change 6: 976.

Brown, B. B. 1987. Territoriality. Pages 505-531 in D. Stokols and I. Altman, editors. Handbook of environmental psychology. Wiley, New York, New York, USA.

Carley, S., T. P. Evans, and D. M. Konisky. 2018. Adaptation, culture, and the energy transition in American coal country. Energy Research and Social Science 37:133-139. https://doi. org/10.1016/j.erss.2017.10.007

Chan, K. M. A., P. Balvanera, K. Benessaiah, M. Chapman, S. DÃaz, E. Gómez-Baggethun, R. Gould, N. Hannahs, K. Jax, S. Klain, G. W. Luck, B. Martín-López, B. Muraca, B. Norton, K. Ott, U. Pascual, T. Satterfield, M. Tadaki, J. Taggart, and N. Turner. 2016. Opinion: why protect nature? Rethinking values and the environment. Proceedings of the National Academy of Sciences 113(6):1462-1465. https://doi.org/10.1073/pnas.1525002113

Chapin, F. S., III, and C. N. Knapp. 2015. Sense of place: a process for identifying and negotiating potentially contested visions of sustainability. Environmental Science and Policy 53:38-46. https:// doi.org/10.1016/j.envsci.2015.04.012

Charli-Joseph, L., J. M. Siqueiros-Garcia, H. Eakin, D. ManuelNavarrete, and R. Shelton. 2018. Promoting agency for socialecological transformation: a transformation-lab in the Xochimilco social-ecological system. Ecology and Society 23 (2):46. https://doi.org/10.5751/ES-10214-230246

Checkland, P., and J. Poulter. 2006. Learning for action: a short definitive account of soft systems methodology and its use for practioners, teachers and students. Wiley and Son, West Sussex, UK.

Cirelli, C. 1997. La transferencia de agua: el impacto en las comunidades origen del recurso. El caso de San Felipe y Santiago, Estado de México. Thesis. Universidad Iberoamericana, Mexico City, Mexico.

Clayton, S., C. Manning, and C. Hodge. 2014. Beyond storms and droughts: the psychological impacts of climate change. American Psychological Association and ecoAmerica, Washington, D.C., USA. [online] URL: https://ecoamerica.org/wp-content/uploads/2014/06/ eA_Beyond_Storms_and_Droughts_Psych_Impacts_of_Climate_Change. pdf

Cone, J., and K. Winters. 2011. Mental models interviewing for more-effective communication: a primer. Oregon Sea Grant, Oregon State University, Corvallis, Oregon, USA. [online] URL: https://seagrant.oregonstate.edu/sgpubs/mental-models-interviewingmore-effective-communication

Doherty, T. J., and S. Clayton. 2011. The psychological impacts of global climate change. American Psychologist 66:265-276. https://doi.org/10.1037/a0023141

Eakin, H., L. A. Bojórquez-Tapia, M. A. Janssen, M. Georgescu, D. Manuel-Navarrete, E. R. Vivoni, A. E. Escalante, A. Baeza- 
Castro, M. Mazari-Hiriart, and A. M. Lerner. 2017. Opinion: urban resilience efforts must consider social and political forces. Proceedings of the National Academy of Sciences 114(2):186-189. https://doi.org/10.1073/pnas.1620081114

Ezcurra, E., M. Mazari-Hiriart, I. Pisanty, and A. G. Aguilar. 2006. La cuenca de México. Aspectos ambientales críticos y sustentabilidad. Fondo de Cultura Económica/Universidad Nacional Autónoma de México, Mexico City, Mexico.

González Pozo, A., E. Ensástiga, F. R. Chiapa Sánchez, and N. Ruz Varas. 2016. Las Chinampas: patrimonio mundial de la Ciudad de México. Patrimonio, Economía Cultural y Educación para la Paz (MEC-EDUPAZ) 1(11):158-190. [online] URL: http://www.revistas.unam.mx/index.php/mecedupaz/article/view/58881

Hardin, R. 1982. Collective action. John Hopkins University Press, Baltimore, Maryland, USA.

Harner, J. 2001. Place identity and copper mining in Sonora, Mexico. Annals of the Association of American Geographers 91 (4):660-680. https://doi.org/10.1111/0004-5608.00264

Javeline, D. 2003. The role of blame in collective action: evidence from Russia. American Political Science Review 97(1):107-121.

Kahneman, D., J. L. Knetsch, and R. H. Thaler. 1991. Anomalies: the endowment effect, loss aversion, and status quo bias. Journal of Economic Perspectives 5(1):193-206. https://pubs.aeaweb.org/ doi/pdf/10.1257/jep.5.1.193

Lai, P.-H., and U. P. Kreuter. 2012. Examining the direct and indirect effects of environmental change and place attachment on land management decisions in the Hill Country of Texas, USA. Landscape and Urban Planning 104:320-328. https://doi. org/10.1016/j.landurbplan.2011.11.007

Lewicka, M. 2011. Place attachment: how far have we come in the last 40 years? Journal of Environmental Psychology 31 (3):207-230. https://doi.org/10.1016/j.jenvp.2010.10.001

Marshall, N., W. N. Adger, C. Benham, K. Brown, M. I Curnock, G. G. Gurney, P. Marshall, P. L Pert, and L. Thiault. 2019. Reef grief: investigating the relationship between place meanings and place change on the Great Barrier Reef, Australia. Sustainability Science 14(3):579-587. https://doi.org/10.1007/s11625-019-00666$\underline{\mathrm{Z}}$

Marshall, N. A., S. E. Park, W. N. Adger, K. Brown, and S. M. Howden. 2012. Transformational capacity and the influence of place and identity. Environmental Research Letters 7(3):034022. https://doi.org/10.1088/1748-9326/7/3/034022

Masterson, V. A., J. P. Enqvist, R. C. Stedman, and M. Tengö. 2019. Sense of place in social-ecological systems: from theory to empirics. Sustainability Science 14(3):555-564. https://doi. org/10.1007/s11625-019-00695-8

Masterson, V. A., R. C. Stedman, J. P. Enqvist, M. Tengö, M. Giusti, D. Wahl, and U. Svedin. 2017. The contribution of sense of place to social-ecological systems research: a review and research agenda. Ecology and Society 22(1):49. https://doi. org/10.5751/ES-08872-220149

Mazari-Hiriart, M., S. Ponce-de-León, Y. López-Vidal, P. IslasMacías, R. I. Amieva-Fernández, and F. Quiñones-Falconi. 2008.
Microbiological implications of periurban agriculture and water reuse in Mexico City. PLoS One 3(5):e2305. https://doi. org/10.1371/journal.pone.0002305

Merlín-Uribe, Y., C. E. González-Esquivel, A. ContrerasHernández, L. Zambrano, P. Moreno-Casasola, and M. Astier. 2013. Environmental and socio-economic sustainability of chinampas (raised beds) in Xochimilco, Mexico City. International Journal of Agricultural Sustainability 11(3):216-233. https://doi.org/10.1080/14735903.2012.726128

Morehart, C. 2018. The political ecology of chinampa landscapes in the Basin of Mexico. Pages 19-39 in E. Holt, editor. Water and power in ancient societies. IEMA Proceedings. State University of New York, Buffalo, New York, USA.

Morgan, M. G., B. Fischhoff, A. Bostrom, and C. J. Atman. 2002. Risk communication: a mental models approach. Cambridge University Press, Cambridge, U.K. https://doi.org/10.1017/ CBO9780511814679

O'Brien, K., and L. Sygna 2013. Responding to climate change: the three spheres of transformation. Proceedings. Transformation in a Changing Climate. 19-21 June 2013, University of Oslo, Oslo, Norway. [online] URL: https://www.sv.uio.no/iss/english/research/ projects/adaptation/publications/1-responding-to-climate-change--three-spheres-of-transformation obrien-and-sygna webversion final. pdf

Pérez Mujica, L. H. 2012. Problemática ambiental de Xochimilco. Thesis. Universidad Nacional Autónoma de México, Mexico City, Mexico.

Rojas Rabiela, T. 1991. La Agricultura en tierras Mexicanas desde sus orígenes hasta nuestros días. Consejo Nacional para la Cultura y las Artes, Mexico City, México.

Romero Lankao, P. 2010. Water in Mexico City: what will climate change bring to its history of water-related hazards and vulnerabilities? Environment and Urbanization 22(1):157-178. https://doi.org/10.1177/0956247809362636

Sack, R. D. 1997. Homo geographicus: a framework for action, awareness, and moral concern. John Hopkins University Press, Balitmore, Maryland, USA.

Scannell, L., and R. Gifford. 2010. Defining place attachment: a tripartite organizing framework. Journal of Environmental Psychology 30(1):1-10. https://doi.org/10.1016/j.jenvp.2009.09.006

Siquieiros-García, J. M., A. M. Lerner, H. C. Eakin, and B. Hernández Aguilar. 2019. A standardization process for mental model analysis in social-ecological systems. Environmental Modelling and Software 112:108-111. https://doi.org/10.1016/j. envsoft.2018.11.016

Stedman, R. C. 2002. Toward a social psychology of place: Predicting behavior from place-based cognitions, attitude, and identity. Environment and Behavior 34(5):561-581. https://doi. org/10.1177/0013916502034005001

Stedman, R. C. 2003. Is it really just a social construction?: The contribution of the physical environment to sense of place. Society and Natural Resources 16(8) 671-685. https://doi. org/10.1080/08941920309189 
Stedman, R. C. 2016. Subjectivity and social-ecological systems: a rigidity trap (and sense of place as a way out). Sustainability Science 11(6):891-901. https://doi.org/10.1007/s11625-016-0388$\mathrm{y}$

Stone, D. A. 2002. Policy paradox: the art of political decision making. W. W. Norton, New York, New York, USA.

Tellman, B., J. C. Bausch, H. Eakin, J. M. Anderies, M. MazariHiriart, D. Manuel-Navarrete, and C. L. Redman. 2018. Adaptive pathways and coupled infrastructure: seven centuries of adaptation to water risk and the production of vulnerability in Mexico City. Ecology and Society 23(1):1 https://doi.org/10.5751/ ES-09712-230101

Tschakert, P., J. Barnett, N. Ellis, C. Lawrence, N. Tuana, M. New, C. Elrick-Barr, R. Pandit, and D. Pannell. 2017. Climate change and loss, as if people mattered: values, places, and experiences. Wiley Interdisciplinary Reviews: Climate Change 8(5). http://doi. org/10.1002/wcc.476

Tschakert, P., N. R. Ellis, C. Anderson, A. Kelly, and J. Obeng. 2019. One thousand ways to experience loss: a systematic analysis of climate-related intangible harm from around the world. Global Environmental Change 55:58-72. https://doi.org/10.1016/j. gloenvcha.2018.11.006

Tschakert, P., R. Tutu, and A. Alcaro. 2013. Embodied experiences of environmental and climatic changes in landscapes of everyday life in Ghana. Emotion, Space and Society 7:13-25. https://doi.org/10.1016/j.emospa.2011.11.001

Twigger-Ross, C. L., and D. L. Uzzell. 1996. Place and identity processes. Journal of Environmental Psychology 16(3):205-220. https://doi.org/10.1006/jevp.1996.0017

Tuan, Y.-F. 1977. Space and place: the perspective of experience. University of Minnesota Press, Minneapolis, Minnesota, USA.

Warsini, S., J. Mills, and K. Usher. 2014. Solastalgia: living with the environmental damage caused by natural disasters. Prehospital and Disaster Medicine 29(1):87-90. https://doi. org/10.1017/S1049023X13009266

Westley, F. R., O. Tjornbo, L. Schultz, P. Olsson, C. Folke, B. Crona, and Ö. Bodin. 2013. A theory of transformative agency in linked social-ecological systems. Ecology and Society 18(3):27. http://dx.doi.org/10.5751/ES-05072-180327

Widdifield, S. G., and J. M. Banister. 2015. Seeing water in early Twentieth-Century Mexico City: Henry Wellge's perspective plan of the city and valley of Mexico, D.F., 1906. Anales del Instituto de Investigaciones Estéticas XXXVII (107):9-35. https://doi. org/10.22201/iie.18703062e.2015.107.2551

Zambrano, L., V. Contreras, M. Mazari-Hiriart, and A. E. ZarcoArista. 2009. Spatial heterogeneity of water quality in a highly degraded tropical freshwater ecosystem. Environmental Management 43(2):249-263. https://doi.org/10.1007/s00267-008-9216-1

Zambrano, L., E. Vega, L. G. Herrera M., E. Prado, and V. H. Reynoso. 2007. A population matrix model and population viability analysis to predict the fate of endangered species in highly managed water systems. Animal Conservation 10(3):297-303. https://doi.org/10.1111/j.1469-1795.2007.00105.x 